\title{
Study on Anatomical Variations in Fissures of Lung by CT Scan
}

\author{
M. Manjunath ${ }^{1} \quad$ M. Vishnu Sharma ${ }^{2} \quad$ Kollanur Janso ${ }^{3}$ Praveen Kumar John ${ }^{4} \quad$ N. Anupama ${ }^{5}$ \\ D.S. Harsha ${ }^{2}$
}

${ }^{1}$ Department of Respiratory Medicine, Navodaya Medical College, Raichur, Karnataka, India

2 Department of Respiratory Medicine, A.J. Institute of Medical Sciences and

Research Center, Kuntikana, Mangalore, Karnataka, India

3 Department of Respiratory Medicine, Amala Institute of Medical

Sciences, Thrissur, Kerala, India

${ }^{4}$ Department of Radio Diagnosis, A.J. Institute of Medical Sciences and Research Center, Kuntikana, Mangalore, Karnataka, India

${ }^{5}$ Department of Physiology, Kasturba Medical College, Mangalore, Manipal Academy of Higher Education, Manipal, Karnataka, India

Address for correspondence M. Vishnu Sharma, Professor and Head, Department of Respiratory Medicine, A J Institute of Medical Sciences, Kuntikana, Mangalore 575004, India (e-mail: drvishnusharmag@gmail.com).

Indian J Radiol Imaging 2021;31:797-804.

\begin{abstract}
Keywords

- accessory fissures

- anatomical variations

- CT scan thorax

- fissures of lung

Introduction Refinements in the modern computed tomography (CT) imaging techniques have led to anatomical variations in the fissures of lung being diagnosed more frequently. So far, majority of the studies conducted are cadaveric. There is paucity of studies in this aspect based on chest CT images. Hence, we undertook this study to find the anatomical variations in the fissures. Prior detection of anatomical abnormalities is important to reduce postoperative complications in lung resection surgeries.

Materials and Methods This was a cross-sectional study conducted over a period of 2 years. Data were collected from the patients who underwent CT scan thorax. Patients in whom normal anatomy of lung was distorted and cases where both lungs were not visualized completely were excluded from the study. All the CT images were reviewed by a single radiologist. The presence or absence of the normal and accessory pulmonary fissures, as well as the continuity of each fissure, was recorded by the radiologist. Data were compiled and analyzed.

Results The study population consisted of 394 (70.4\%) males and 166 (29.6\%) females, totaling 560 cases. Fissural variations were detected in $22.9 \%(n=128)$. Also, $17.5 \%(n=98)$ fissural variations were seen in males and $5.4 \%(n=30)$ fissural variations were seen in females. Further, $54.7 \%(n=70)$ of variations were detected in the right lung and $45.3 \%(n=58)$ in the left lung. The most common fissural variation noted was right incomplete oblique fissure with a frequency of $8.4 \%$ cases $(n=47)$. The most common accessory fissure detected was inferior accessory fissure. Total 22 cases were detected in both the lungs, 17 cases in male and 5 in female.

Conclusion Anatomical variations in fissures were found to be more in the right lung than the left lung. Accessory fissures were detected in higher incidence on the right side.
\end{abstract}

published online

January 11, 2022
DOI https://doi.org/ 10.1055/s-0041-1741045. ISSN 0971-3026. (c) 2022. Indian Radiological Association. All rights reserved.

This is an open access article published by Thieme under the terms of the Creative Commons Attribution-NonDerivative-NonCommercial-License, permitting copying and reproduction so long as the original work is given appropriate credit. Contents may not be used for commercial purposes, or adapted, remixed, transformed or built upon. (https://creativecommons.org/ licenses/by-nc-nd/4.0/)

Thieme Medical and Scientific Publishers Pvt. Ltd., A-12, 2nd Floor, Sector 2, Noida-201301 UP, India 


\section{Introduction}

During embryonic development, visceral pleura invaginates the pulmonary parenchyma forming the lobes. Majority of the fissures that separate individual bronchopulmonary buds get obliterated during embryonic development except along the two planes in the right lung that form the horizontal and oblique fissure ${ }^{1}$ and on the left, oblique fissure remains. Developmental variations can occur in the fissures. Either a complete or partial obliteration during development can lead to absence or incomplete fissure. Nonobliteration of spaces between bronchopulmonary buds can lead to accessory fissure. ${ }^{1}$

Fissures in the lung help easy movement of the lobes in relation to each other, so that each lobe and segment will expand properly during respiration in a uniform manner. Incomplete fissures may lead to improper expansion of lung, which may contribute to hypoxia in patients with intrathoracic diseases. ${ }^{2}$

Anatomical variations in fissures may lead to changes in the patterns of collapse of a lobe or segment of lung in patients with endobronchial lesions. Fissural variations may lead to atypical or abnormal appearance of pleural effusion in chest radiograph. An incomplete major fissure may lead to abnormal radiological appearance of pleural fluid encystment within the fissure. Fissural variations may also change the spread of disease within the lobes of the lung, especially in case of pneumonia and malignancy in the initial stages. ${ }^{3} \mathrm{~A}$ proper fissure often limits the spread of pneumonia to adjacent lobes. When a fissure is incomplete or absent, pneumonia and malignancy can easily spread to the adjacent lobes.

Knowledge about the anatomical variation is also important in interpreting radiological images. Position of the normal fissures is often used as a reliable landmark for localizing intrathoracic lesions. ${ }^{4}$ Exact anatomical localization of intrathoracic disease processes by computed tomography $(\mathrm{CT})$ scan is important to determine the next optimal diagnostic investigation and treatment modality. CT scan of thorax is also useful in diagnosing lesions in the pleura and in the fissures, which could be mistaken for lung parenchymal lesions in patients with incomplete, absent, or accessory fissures. Knowledge regarding the anatomical variations in fissures and radiological identification of these variations is essential for proper localization of intrathoracic and lung parenchymal lesions, to determine the extent of the disease, and to differentiate accessory fissures from other anatomical structures or lesions.

Detection of anatomical variations in fissures by CT scan prior to surgery is important to plan lobectomy and segmental resection. Presence of incomplete fissure may lead to technical difficulty in separating the lobes and may lead to increased risk of postoperative air leak, blood loss, and bronchopleural fistula. ${ }^{3}$ Hence, it is very important for radiologists to detect and report any anatomical abnormalities in fissures, especially in patients who have to undergo lung resection surgery.

Refinements in modern imaging techniques have led to an increase in the frequency of anatomical variations in the fissures of lung being diagnosed. Various modern techniques in the thoracic CT scan can now delineate the anatomy up to the subsegmental level in the lungs. In CT scan, accessory fissure needs to be differentiated from margins of costal cartilages, fibrotic bands, scars, collapsed visceral pleural margin of a small pneumothorax, margin of bullae, and normal fissure. ${ }^{4}$

So far majority of the studies conducted are cadaveric. There is paucity of studies in this aspect based on chest CT images. Hence, we undertook this study.

\section{Aims and Objectives}

- To find anatomical variations in fissures if any, in patients undergoing CT scan thorax.

- To compare the anatomical variations in fissures in both genders.

- To compare the anatomical variations in fissures in both lungs.

\section{Materials and Methods}

This was a cross-sectional study conducted from December 2013 to December 2015. Data were collected from the patients undergoing CT scan thorax in the Department of Radio Diagnosis in our hospital. Patients in whom normal anatomy of lung was distorted by disease or any other pathology and cases where both lungs were not visualized completely due to disease or previous surgery were excluded from the study. Total 560 cases were included in the study.

All scans were performed using 64-Slice Volume CT Scanner, with a Light Speed 16 multidetector CT (GE Healthcare, Milwaukee, WI) using $1.25 \mathrm{~mm}$ collimation and $0.625 \mathrm{~mm}$ reconstruction interval, $120 \mathrm{kVp}$, and average $320 \mathrm{~mA}$ tube current with pitch of 1.375 . Contrast used was 120 to $150 \mathrm{~mL}$ of Omnipaque 300 (GE Healthcare, Princeton, NJ) nonionic intravenous (IV) contrast material, administered with a power injector at a rate of $4 \mathrm{~mL} / \mathrm{s}$ through an antecubital vein. Scanning was initiated with a delay time of 30 seconds after beginning the IV contrast material injection. The subject was asked to hold the breath at the end of deep inspiration and scan was performed from lung base to the apex. Multiplanar reformation (MPR) images and axial images were obtained.

All the CT scan images were interpreted by a single radiologist who had 10 years of experience in interpretation of thoracic CT scan. The presence or absence of the normal and accessory pulmonary fissures, as well as the continuity of each fissure, was recorded by the radiologist as per the classification by Craig and Walker. ${ }^{5}$ Specifically, the continuity, frequency, and morphology of all the visualized fissures were noted. A thorough search was made by the radiologist to find out the presence or absence of fissures. These fissures included the normal fissures, namely right major fissure, left major fissure, and right horizontal fissure. Accessory fissures include superior and inferior accessory fissures on both sides, accessory fissures between medial and lateral segments of the middle lobe on right side, accessory fissures 
between superior and inferior segments of the lingula on left side, accessory fissures between anterior basal and lateral basal segments of the lower lobes on both sides, left horizontal fissure, and azygos fissure. ${ }^{4}$ Superior accessory fissure is the accessory fissure between superior and basal segment of the lower lobe. Inferior accessory fissure separates the medial basal segment from the rest of the segments of lower lobe. The left horizontal fissure is an accessory fissure that separates lingula from the rest of the left upper lobe. The azygos vein penetrates through the upper lobe of the right lung and drags the parietal and visceral pleura with it, thus creating an accessory fissure, known as the "azygos fissure," which can have either a vertical or an oblique course. Azygos fissure occurs only on the right side.

Statistical Package for Social Sciences (version 13) software was used for analysis of the data. Descriptive statistics was used to describe the total number of normal and accessory fissures; their presence or incompleteness was noted. Potential differences in gender and side of the lung were assessed using chi-squared test of significance. Fisher's exact test was used for analysis of grouped data. In all of the above tests, $p$-value of less than 0.01 was accepted as indicating statistical significance.

\section{Results}

Total 560 CT scan thorax were carefully reviewed for any variations in fissural anatomy. The study population consisted of $394(70.4 \%)$ males and 166 (29.6\%) females. Fissural variations were detected in $22.9 \%(n=128)$ ( $($ Table 1). Also, $17.5 \%$ $(n=98)$ fissural variations were seen in males and $5.4 \%$ $(n=30)$ fissural variations were seen in females. Further, $54.7 \%(n=70)$ of variations were detected in the right lung and $45.3 \%(n=58)$ in the left lung. The most common fissural variation noted was right incomplete oblique fissure (-Fig. 1) with a frequency of $8.4 \%$ cases $(n=47)$. It was seen in $7.9 \%$ $(n=31)$ cases in males and $9.6 \%(n=16)$ cases in females. The second most common fissural variation was incomplete oblique fissure in the left lung ( - Fig. 2 ) in 6.3\% cases $(n=35)$. It was seen in $7.9 \%(n=31)$ of males and $2.4 \%(n=4)$ of females in the study population (-Table $\mathbf{2}$ ).

Accessory fissures were noted in $7.3 \%$ cases $(n=41)$. Of these, $3.2 \%$ cases $(n=18)$ were detected in the right lung and $4.1 \%(n=23)$ cases were detected in the left lung. In the right lung, superior accessory fissure was detected in 6 cases, and 12 cases $(66.7 \%)$ of inferior accessory fissure were detected (-Tables 3 and $\mathbf{4}$ ).

Table 1 Gender-wise anatomical variations in fissure distribution in right and left lungs

\begin{tabular}{|l|l|l|}
\hline Lung & No. of cases & Percent \\
\hline Right lung & 70 & 54.7 \\
\hline Left lung & 58 & 45.3 \\
\hline Males & 98 & 17.5 \\
\hline Females & 30 & 5.4 \\
\hline
\end{tabular}

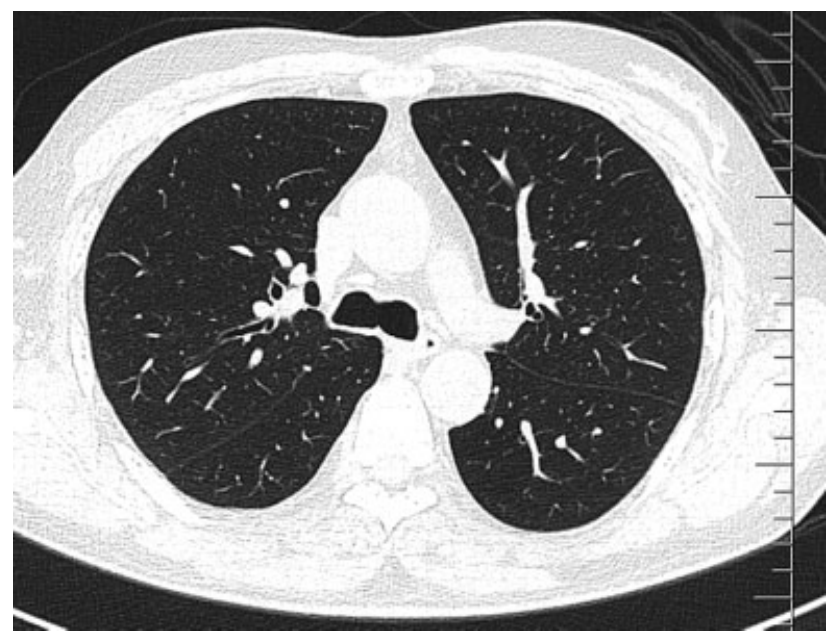

Fig. 1 Incomplete right major fissure.

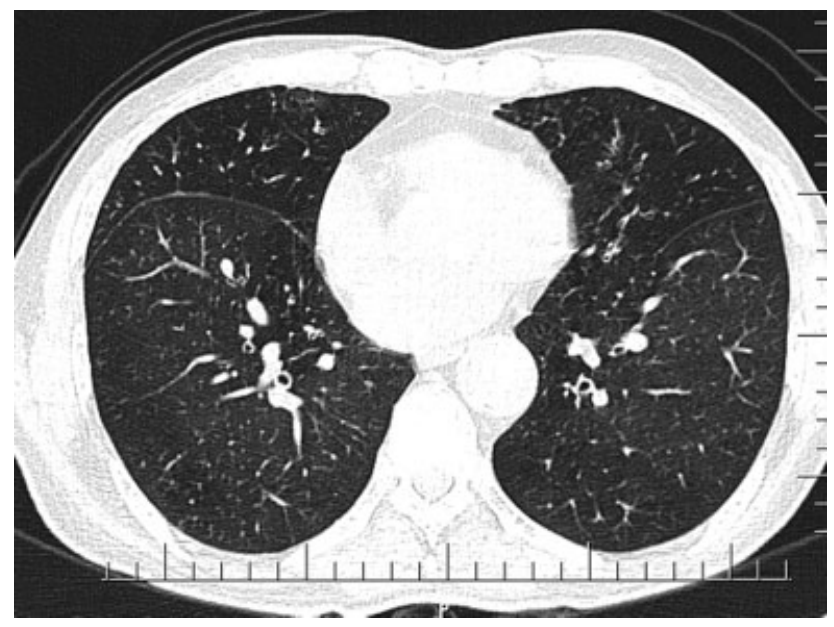

Fig. 2 Incomplete left major fissure.

Gender-wise distribution of right lung accessory fissure showed four cases of superior accessory fissure (-Fig. $\mathbf{3}$ ) in males and two cases in females. Ten cases of inferior accessory fissure in males and two in females (-Table 3 ) were found. Also, $4.1 \%(n=18)$ accessory fissures were detected in left lung. Out of this, superior accessory fissures in 5 cases were seen, that is, $21.7 \%$ of accessory fissures were detected in the left lung, while 10 cases (43.5\%) of inferior accessory fissure were detected in the left lung. Gender-wise distribution of left lung accessory fissure showed five cases of superior accessory fissure in males and none in female. Seven cases of inferior accessory fissure were in males and three in females (- Tables $\mathbf{3}$ and $\mathbf{4}$ ).

Inferior accessory fissure was the most common accessory fissure detected. Total 22 cases were detected in both lungs. Seventeen cases were in males and five in females. There were 12 cases of inferior accessory fissure in the right lung (-Fig. 4): 10 cases in males and 2 in females. Ten cases of inferior accessory fissure were found in the left lung (-Fig. 5): seven cases in males and three in females. Azygos 
Table 2 Distribution of different fissural variations

\begin{tabular}{|l|l|l|l|}
\hline Variation & $n$ & Male & Female \\
\hline Incomplete oblique fissure right side & $47(8.4 \%)$ & $31(7.9 \%)$ & $16(9.6 \%)$ \\
\hline Incomplete oblique fissure left side & $35(6.3 \%)$ & $31(7.9 \%)$ & $4(2.4 \%)$ \\
\hline Right minor fissure incomplete & $3(0.5 \%)$ & $2(0.5 \%)$ & $1(0.4 \%)$ \\
\hline Right minor fissure absent & $2(0.4 \%)$ & $2(0.5 \%)$ & Nil \\
\hline Accessory fissure right side & $18(3.2 \%)$ & $14(3.6 \%)$ & $4(2.4 \%)$ \\
\hline Accessory fissure left side & $23(4.1 \%)$ & $18(4.6 \%)$ & $5(3 \%)$ \\
\hline Total & $128(22.9 \%)$ & $98(17.5 \%)$ & $30(5.4 \%)$ \\
\hline
\end{tabular}

Table 3 Accessory fissures

\begin{tabular}{|l|l|l|l|}
\hline Accessory fissure & $\boldsymbol{n}$ & Right side & Left side \\
\hline Superior & 11 & 6 & 5 \\
\hline Inferior & 22 & 12 & 10 \\
\hline Azygos & 1 & 1 & Nil \\
\hline Minor fissure & 7 & Nil & 7 \\
\hline Total & 41 & 19 & 22 \\
\hline
\end{tabular}

fissure was seen in one case ( - Fig. 6) and minor fissure in the

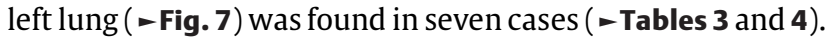

Prevalence of incomplete oblique fissure was more in the right side when compared with the left side. Prevalence of accessory fissure was more in the left lung compared with the right. But these differences were statistically not significant (-Tables 5, 6-7). The difference in the prevalence of incomplete oblique fissure (major fissure) in the left lung among males and females was statistically significant (-Tables 5,6,7). We had two cases of absent right horizontal fissure ( - Fig. 8) and 3 cases of incomplete right minor fissure (-Figs. 9 \& 10).

\section{Discussion}

Refinements in the modern CT imaging techniques have led to anatomical variations in the fissures of lung being diagnosed more frequently. Most of the studies are based on

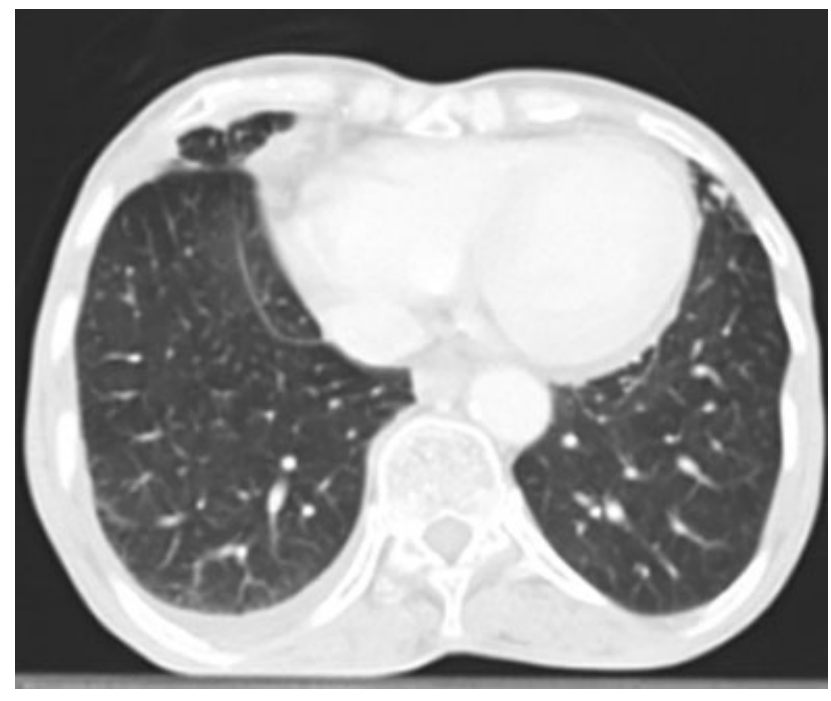

Fig. 3 Right superior accessory fissure.

cadavers. $^{6-12}$ There is a paucity of studies on anatomical variations based on CT scans in Indian population.

Detection of pulmonary fissures and variations in the fissural anatomy in CT scan images is not easy because the fissures are usually very thin membrane-like structures with low contrast; they vary in intensity and partial volume effect of the fissures. Besides, fissures may get deformed or distorted due to intrathoracic diseases. High-resolution CT (HRCT) scan of thorax is essential for better visualization

Table 4 Distribution of types of accessory fissures and their gender distribution

\begin{tabular}{|l|l|l|l|}
\hline Accessory fissure present & Male & Female & Total \\
\hline Accessory fissure right side & $14(36 \%)$ & $4(24 \%)$ & $18(32 \%)$ \\
\hline Superior accessory fissure right side & $4(71.4 \%)$ & $2(50 \%)$ & $6(66.7 \%)$ \\
\hline Inferior accessory fissure right side & $10(71.4 \%)$ & $2(50 \%)$ & $12(66.7 \%)$ \\
\hline Accessory fissure left side & $18(4.6 \%)$ & $5(3 \%)$ & $23(4.1 \%)$ \\
\hline Superior accessory fissure left side & $5(27.8 \%)$ & Nil & $5(21.7 \%)$ \\
\hline Inferior accessory fissure left side & $7(38.9 \%)$ & $3(60 \%)$ & $10(43.5 \%)$ \\
\hline Left side minor fissure & $6(33.3 \%)$ & $1(20 \%)$ & $7(30.4 \%)$ \\
\hline
\end{tabular}




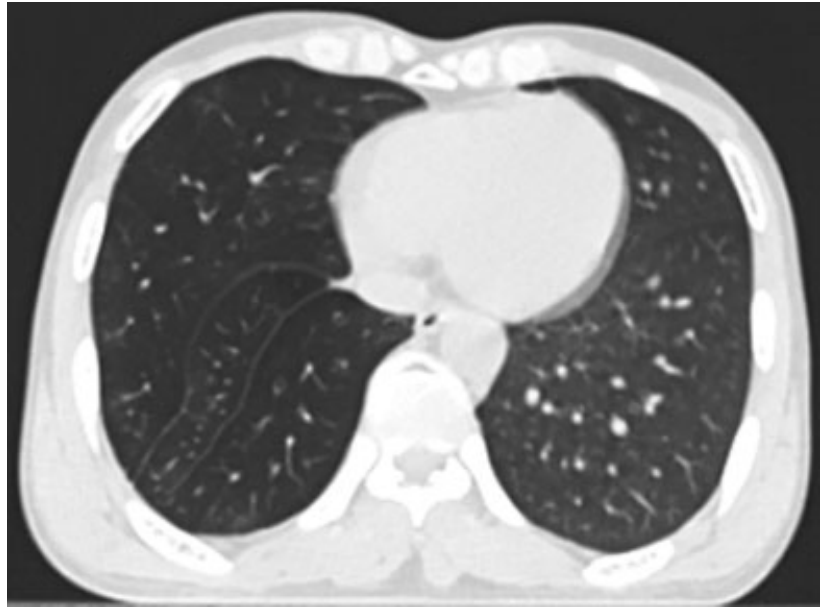

Fig. 4 Right inferior accessory fissure.

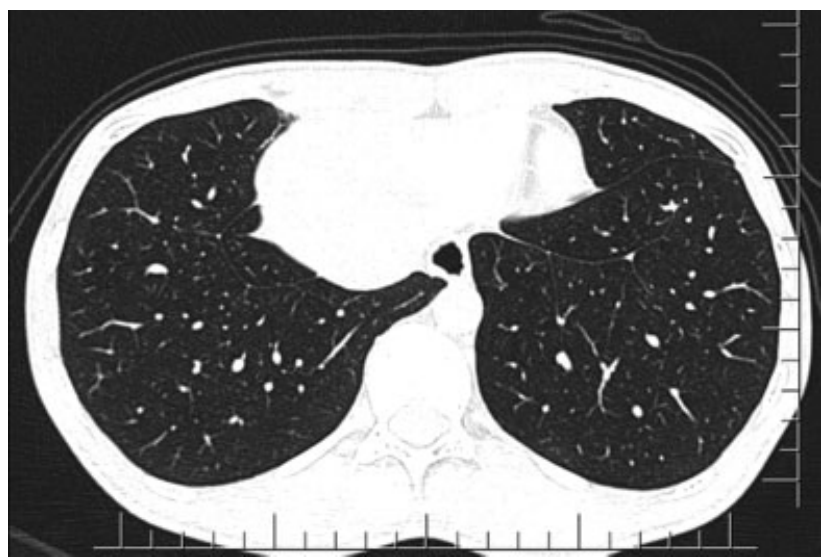

Fig. 5 Left inferior accessory fissure.

of fissures where it is usually seen as a thin line or as a relatively avascular region or both. ${ }^{13}$

In video-assisted thoracic surgery, the surgeon cannot palpate or visualize the whole lung as in the case of open thoracotomy. Hence, incomplete fissure or accessory fissure may lead to increased incidence of complications during video-assisted thoracic surgery. Prior knowledge of fissural anatomy and exact localization of the diseased part of lung in relation to the fissures will reduce the complications during video-assisted lung resection surgery. ${ }^{14}$

Knowing the exact fissural anatomy is important for segmental and lobar resections. If fissure is incomplete or

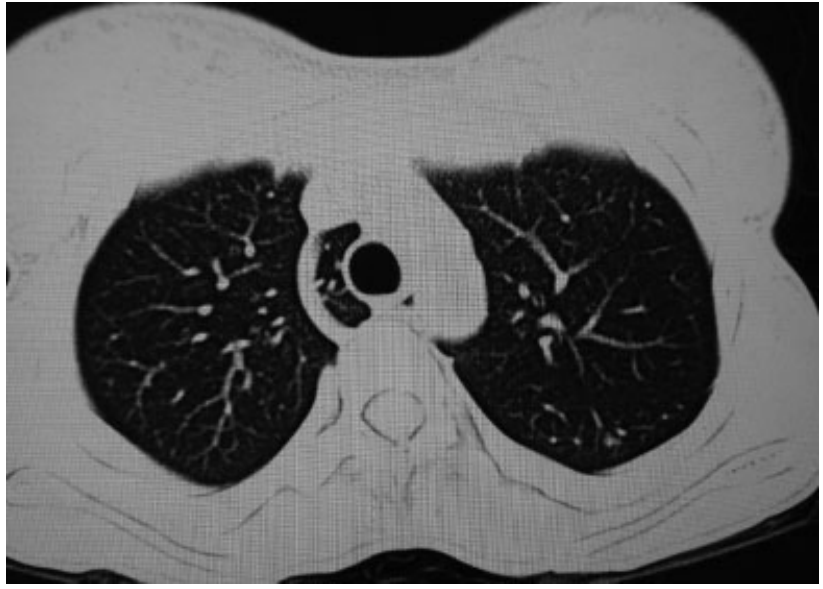

Fig. 6 Azygos fissure.

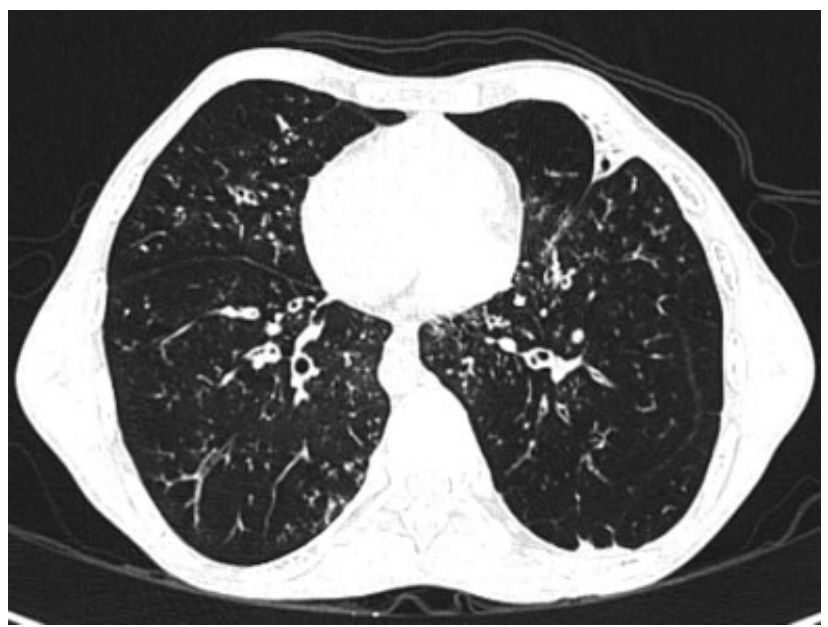

Fig. 7 Accessory left minor fissure.

absent, then lung parenchymal dissection needs to be done, which will increase the operative time and lead to complications like bleeding, postoperative air leak, and bronchopleural fistula. ${ }^{14}$

This study was conducted in our institute involving 560 subjects. It was a cross-sectional analysis of chest CT scans of 560 patients. In this study, $70.45 \%$ cases were males $(n=394)$ and $29.6 \%$ were females $(n=166)$.

Out of 560 study population, $18.92 \%$ subjects $(n=106)$ had variation in the fissural anatomy. The total number of

Table 5 -Value for the comparison in Table 4

\begin{tabular}{|l|l|l|l|l|l|}
\hline & $\begin{array}{l}\text { Chi-squared } \\
\text { test }\left(x^{2}\right)\end{array}$ & $p$-Value & $\begin{array}{l}\text { Fisher's exact } \\
\text { test }\end{array}$ & $\begin{array}{l}\text { Chi-squared } \\
\text { test }\left(x^{2}\right)\end{array}$ & $p$-Value \\
\hline Right lung incomplete oblique fissure * GEN & 0.476 & 0.490 & Not significant & - & - \\
\hline Left lung incomplete oblique fissure * GEN & 5.939 & 0.015 & Significant & - & - \\
\hline Absent minor fissure right lung * GEN & 0.399 & 0.528 & Not significant & - & - \\
\hline Accessory fissure right lung* GEN & 0.491 & 0.483 & Not significant & - & - \\
\hline Accessory fissure left lung* GEN & 0.718 & 0.397 & Not significant & - & - \\
\hline
\end{tabular}


Table 6 Gender-based comparison of prevalence of right lung anatomical abnormalities $(n=560)$

\begin{tabular}{|l|l|l|l|l|}
\hline Abnormality & Male (\%) & Female (\%) & Prevalence (\%) & $p$-Value \\
\hline Incomplete oblique fissure & $31(5.5)$ & $16(2.9)$ & $47(8.4)$ & $>0.05$ \\
\hline Incomplete minor fissure & $3(0.5)$ & $0(0)$ & $3(0.5)$ & $>0.05$ \\
\hline Absence of minor fissure & $1(0.2)$ & $1(0.2)$ & $2(0.4)$ & $>0.05$ \\
\hline Presence of accessory fissure & $14(2.5)$ & $4(0.7)$ & $18(3.2)$ & $>0.05$ \\
\hline Superior accessory fissure & $4(0.7)$ & $2(0.4)$ & $6(1.1)$ & \\
\hline Inferior accessory fissure & $10(1.7)$ & $2(0.4)$ & $12(2.1)$ & \\
\hline
\end{tabular}

Table 7 Gender-based comparison of prevalence of left lung anatomical abnormalities $(n=560)$

\begin{tabular}{|l|l|l|l|l|}
\hline Abnormality & Male (\%) & Female (\%) & Prevalence (\%) & $p$-Value \\
\hline Incomplete oblique fissure & $31(5.5)$ & $4(0.8)$ & $35(6.3)$ & $<0.05^{*}$ \\
\hline Presence of accessory fissure & $18(3.2)$ & $5(0.9)$ & $23(4.1)$ & \\
\hline Superior accessory fissure & $5(0.9)$ & $0(0)$ & $5(0.9)$ & $>0.05$ \\
\hline Inferior accessory fissure & $7(1.2)$ & $3(0.6)$ & $10(1.8)$ & \\
\hline Azygos fissure & $0(0)$ & $1(0.1)$ & $1(0.1)$ & \\
\hline Left side minor fissure & $6(1.2)$ & $1(0.1)$ & $7(1.3)$ & \\
\hline
\end{tabular}

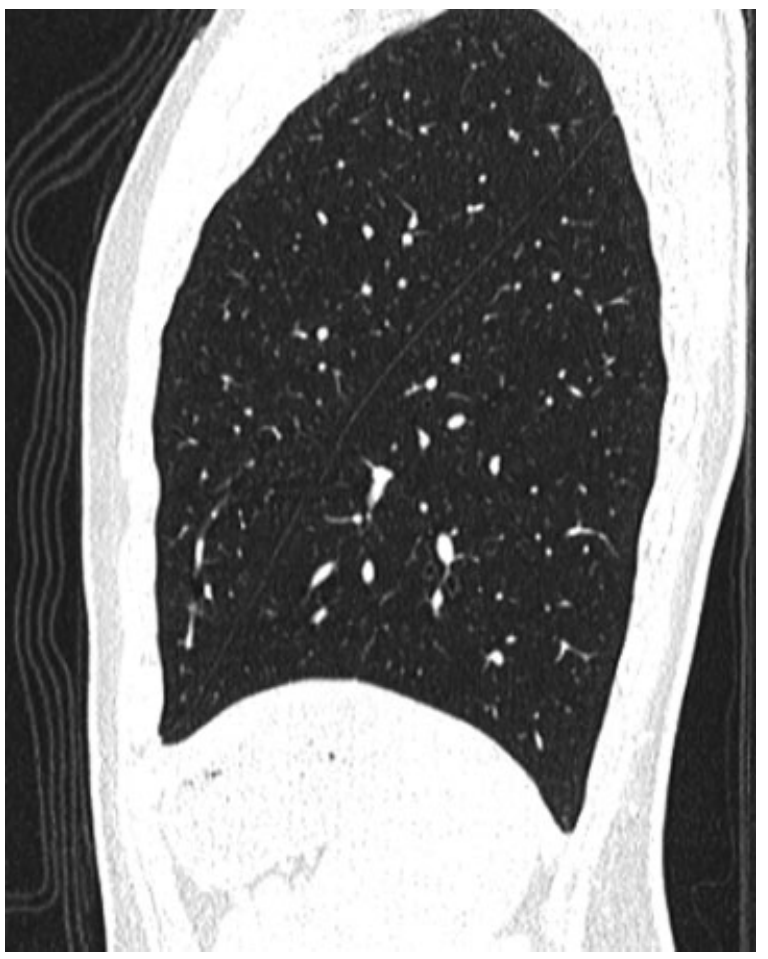

Fig. 8 Absent right horizontal fissure.

fissural variations was found to be 128 in 106 subjects. The right lung had $54.7 \%(n=70)$ variations and left lung had 45.35\% $(n=58)$ variations in fissural anatomy. Previous studies have also showed that anatomical variations are not uncommon. Both the lungs had almost equal incidence of abnormalities in some of these studies. ${ }^{13,15,16}$

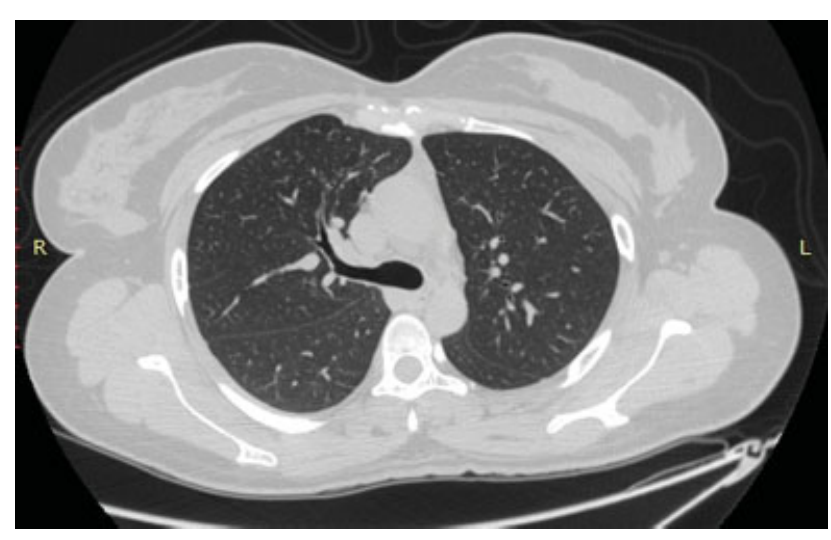

Fig. 9 Incomplete right horizontal fissure.

In our study, out of 128 variations, the most common type of anatomical variation was incomplete major fissure on the right side $(36.7 \%, n=47)$. This is comparable with a study by Heřmanová et $\mathrm{al}^{17}{ }^{17}$ where a retrospective analysis of HRCT of 250 patients was conducted. In that study, incomplete right major fissure was found in $35 \%$ of cases. Another study conducted by Aziz et $\mathrm{al}^{18}$ in 622 patients showed that incomplete right major fissure was the most common fissural variation (48\%).

Incomplete left major fissure was found in $27.3 \%(n=35)$ of cases in our study. A study conducted on 1,000 patients by Mahmut and Nishitani ${ }^{19}$ showed the presence of an incomplete major fissure on the left side in $19.2 \%$ cases. A study by Heřmanová et al ${ }^{17}$ reported incomplete left major fissure in $24 \%$ of cases.

Among the total number of fissural variations $(n=128)$, $2.3 \%$ cases of incomplete horizontal fissure and $1.56 \%$ absent 


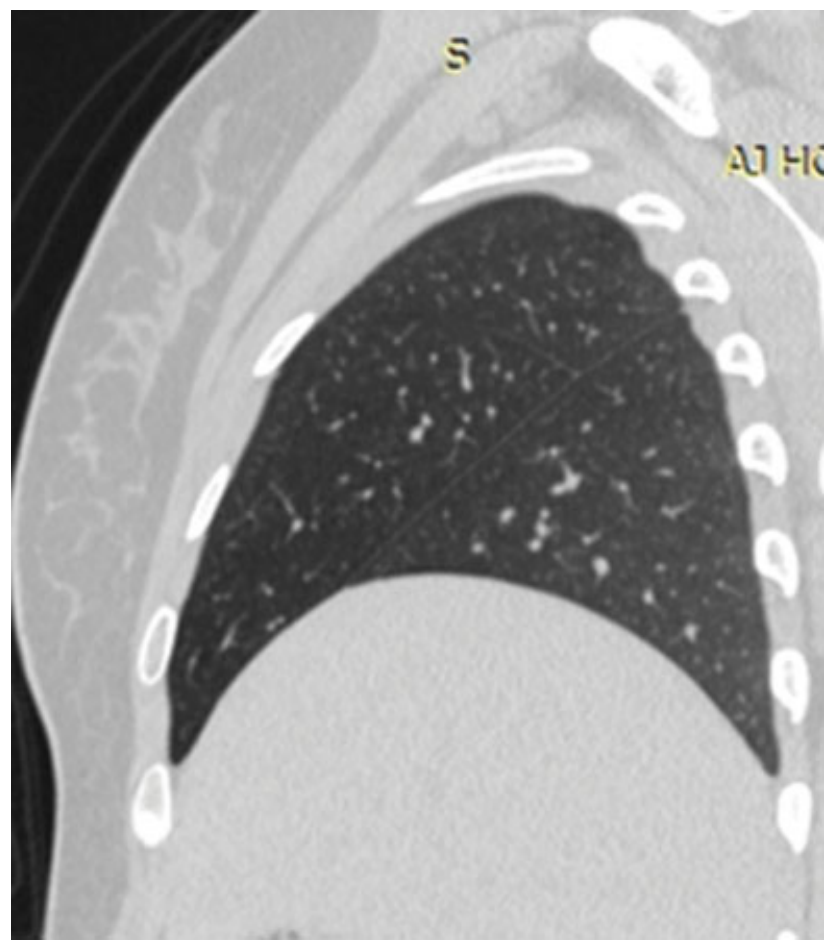

Fig. 10 Incomplete right minor fissure.

horizontal fissure were detected in our study. Previous studies reported a higher incidence of absent or incomplete horizontal fissure. ${ }^{20-23}$ This may be due to racial difference in incidence and different characteristics of study population.

An incomplete fissure can change the appearance of pleural effusion on chest radiograph. ${ }^{24}$ Pleural fluid usually tracks along the fissures. In patients with incomplete fissure, pleural fluid cannot track. ${ }^{23}$ Wherever the fissure is present, pleural fluid is free to track. This may lead to the appearance of a peripheral opacity with a sharp medial edge within the lung. When both the horizontal and the oblique fissures are incomplete in a patient with pleural effusion, the classic "middle lobe stair-step" pattern may be seen in chest radiograph. ${ }^{3}$ This appearance is due to the pleural fluid tracking into the areas wherever the fissure is present. In patients with incomplete fissures, infection may spread easily to the adjacent parts of the lung. ${ }^{25}$ A well-formed fissure helps to limit the spread of pneumonia to adjacent lobes as the continuity is sealed by the pleural reflection.

A study was done by Gerard J. Criner ${ }^{26}$ for assessing the implications of integrity of fissures and lung volume reduction surgery. Patients with well-formed fissure who underwent endobronchial valve placement were found to have incremental improvements in lung function when compared with those who had incomplete fissures. This indicates fissures may help in proper and uniform expansion of the lung. A study done by Gómez-Caro and coworkers found that an incomplete fissure is a risk factor for postoperative air leakage following lobectomy and lung resection surgeries. ${ }^{27}$

In our study, 41 cases of accessory fissures were detected. Frequency of accessory fissure was found to be more common in the left lung $(n=23)$. Inferior accessory fissure
( $n=22$, right-12, left-10) was the most common accessory fissure detected. The second most frequent accessory fissure detected was superior accessory fissure ( $n=11$, right- 6 , left5). A left minor fissure was found in seven cases and azygos fissure in one case.

In the majority, azygos lobe is asymptomatic. Azygos lobe sometimes may mimic a disease pattern or malignancy in chest radiograph. ${ }^{28}$ Aneurysm of azygos vein and spontaneous pneumothorax have been reported. ${ }^{29,30}$ Pneumonia or malignancy of the azygos lobe may not spread readily into adjacent lobes or segments. ${ }^{31}$ Case reports indicate that in primary malignancy in azygos lobe, metastasis and spread to adjacent structure is often rare and delayed.

A similar study done by Ariyürek et al $^{13}$ detected 69 accessory fissures out of 443 cases. In their study, inferior accessory fissure was the most common accessory fissure that was seen in 40 patients ( 38 on the right side, 2 on the left side). A study by Yildiz et $\mathrm{al}^{16}$ based on HRCT was done to find the frequency of accessory fissures in 115 patients. In this study, 44 accessory fissures were found in 115 cases. Inferior accessory fissure (12\%) was the most common accessory fissure, which is comparable with our results.

Accessory fissure should be differentiated from fibrotic bands in the lung. ${ }^{13}$ Pneumonia or malignancy of the segment having accessory fissure may not spread readily into the adjacent lobes or segments. In primary malignancy involving a segment bounded by accessory fissure, metastasis and spread to adjacent structure is often rare and delayed. So having an accessory fissure may be advantageous to contain the spread of disease within the lung.

Anatomical variations in the fissure are not uncommon. With newer imaging techniques, it is easy to identify these abnormalities. Three-dimensional (3D) reconstructions of thoracic image include MPR, maximum intensity projection (MIP), minimum intensity projection, 3D surface-shaded display, and volume rendering (VR) images. ${ }^{32}$ This 3D reconstruction provides all information in a single radiologic study, which is easy to understand and interpret. These images can be viewed in a variety of display formats, including standard axial images, reconstructed images in any plane, and high-quality 3D images. 3D VR images provide more accurate anatomy of intrathoracic structures. Fissures are visualized with MIP, MPR, and VR images. ${ }^{14}$ Thus, any anatomical variation in the intrathoracic structures can be easily identified. This is essential before any thoracic surgery and is crucial before video-assisted thoracic surgery to avoid any complications. ${ }^{14}$

\section{Conclusions}

Anatomical variations in fissures were found to be more in the right lung than the left lung. An incomplete right oblique fissure was the most common fissural abnormality detected. An incomplete left oblique fissure was the second most common fissural abnormality. Accessory fissures were detected in higher incidence on the right lung. Inferior accessory fissure was the most common accessory fissure noted. There was no significant gender-wise difference in the incidence of incomplete and accessory fissures. 


\section{Limitations of the Study}

This study had a small sample size and the study group did not represent the population sample size. A population survey of healthy young adults would be better but the ethical issue is radiation exposure.

\section{Financial Support and Sponsorship}

Nil.

Conflicts of Interest

There are no conflicts of interest.

\section{References}

1 Sadler TW. Langman's Medical Embryology. 11th ed. Baltimore, Maryland: Lippincott Williams \& Wilkins; 2004:203-205

2 Magadum A, Dixit D, Bhimalli S. Fissures and lobes of lung - an anatomical study and its clinical significance. Int J Curr Res Rev 2015;7:8-12

3 Tarver RD. How common are incomplete pulmonary fissures, and what is their clinical significance? AJR Am J Roentgenol 1995;164 (03):761

4 Cronin P, Gross BH, Kelly AM, Patel S, Kazerooni EA, Carlos RC. Normal and accessory fissures of the lung: evaluation with contiguous volumetric thin-section multidetector CT. Eur J Radiol 2010;75(02):e1-e8

5 Craig SR, Walker WS. A proposed anatomical classification of the pulmonary fissures. J R Coll Surg Edinb 1997;42(04):233-234

6 Mamatha Y, Murthy CK, Prakash BS. Study of morphological variations of fissures and lobes of lung. Int J Anat Res 2016; 4:1874-1877

7 Arora AK, Verma P, Kullar JS, Sharma RK, Singla R, Mahajan A. Variations of fissures of lungs. Rev Argde Anat Clin 2012;4:50-56

8 Meenakshi S, Manjunath KY, Balasubramanyam V. Morphological variations of the lung fissures and lobes. Indian J Chest Dis Allied Sci 2004;46(03):179-182

9 Prakash, Bhardwaj AK, Sashirekha M, Suma HY, Krishna GG, Singh G. Lung morphology: a cadaveric study in Indian population. Ital J Anat Embryol 2010;115:235-240

10 Bhimai Devi N, Narasinga Rao B, Sunitha V. Morphological variations of lung-a cadaveric study in north coastal Andhra Pradesh. Int J Biol Med Res 2011;2:1149-1152

11 Jacob SM, Pillay M. Variations in the inter-lobar fissures of lungs obtained from cadavers of South Indian origin. Int J Morphol 2013;31:497-499

12 George BM, Nayak SB, Marpalli S. Morphological variations of the lungs: a study conducted on Indian cadavers. Anat Cell Biol 2014; 47(04):253-258

13 Ariyürek OM, Gülsün M, Demirkazik FB. Accessory fissures of the lung: evaluation by high-resolution computed tomography. Eur Radiol 2001;11(12):2449-2453
14 Gülsün M, Ariyürek OM, Cömert RB, Karabulut N. Variability of the pulmonary oblique fissures presented by high-resolution computed tomography. Surg Radiol Anat 2006;28(03):293-299

15 Proto AV, Ball JB Jr. Computed tomography of the major and minor fissures. AJR Am J Roentgenol 1983;140(03):439-448

16 Yildiz A, Gölpinar F, Calikoğlu M, Duce MN, Ozer C, Apaydin FD. HRCT evaluation of the accessory fissures of the lung. Eur J Radiol 2004;49(03):245-249

17 Heřmanová Z, Ctvrtlík F, Heřman M. Incomplete and accessory fissures of the lung evaluated by high-resolution computed tomography. Eur J Radiol 2014;83(03):595-599

18 Aziz A, Ashizawa K, Nagaoki K, Hayashi K. High resolution CT anatomy of the pulmonary fissures. J Thorac Imaging 2004;19 (03):186-191

19 Mahmut M, Nishitani H. Evaluation of pulmonary lobe variations using multidetector row computed tomography. J Comput Assist Tomogr 2007;31(06):956-960

20 Raasch BN, Carsky EW, Lane EJ, O'Callaghan JP, Heitzman ER. Radiographic anatomy of the interlobar fissures: a study of 100 specimens. AJR Am J Roentgenol 1982;138(06):1043-1049

21 Hayashi K, Aziz A, Ashizawa K, Hayashi H, Nagaoki K, Otsuji H. Radiographic and CT appearances of the major fissures. Radiographics 2001;21(04):861-874

22 Berkmen YM, Auh YH, Davis SD, Kazam E. Anatomy of the minor fissure: evaluation with thin-section CT. Radiology 1989;170(3 Pt 1):647-651

23 Lukose R, Paul S, Sunitha, et al. Morphology of the lungs: variations in the lobes and fissures. Biomedicine 1999;19:227-232

24 Frija J, Schmit P, Katz M, Vadrot D, Laval-Jeantet M. Computed tomography of the pulmonary fissures: normal anatomy. J Comput Assist Tomogr 1982;6(06):1069-1074

25 Webb R, Higgins CB. The pleura and pleural disease (Ch-26). In: Thoracic Imaging: Pulmonary and Cardiovascular Radiology. 2nd ed. Philadelphia, PA: Lippincott Williams \& Wilkins; 2011:616-634

26 Criner GJ, Cordova F, Sternberg AL, Martinez FJ. The National Emphysema Treatment Trial (NETT) Part II: lessons learned about lung volume reduction surgery. Am J Respir Crit Care Med 2011; 184(08):881-893

27 Gómez-Caro A, Calvo MJ, Lanzas JT, Chau R, Cascales P, Parrilla P. The approach of fused fissures with fissureless technique decreases the incidence of persistent air leak after lobectomy. Eur J Cardiothorac Surg 2007;31(02):203-208

28 Felson B. The azygos lobe: its variation in health and disease. Semin Roentgenol 1989;24(01):56-66

29 Caceres J, Mata JM, Andreu J. The azygos lobe: normal variants that may simulate disease. Eur J Radiol 1998;27(01):15-20

30 Villanueva A, Cáceres J, Ferreira M, Broncano J, Pallisa E, Bastarrika G. Migrating azygos vein and vanishing azygos lobe: MDCT findings. AJR Am J Roentgenol 2010;194(03):599-603

31 Patil SJ. Azygos lobe -a review. Int J Clin Surg Adv 2013;1:17-19

32 Calhoun PS, Kuszyk BS, Heath DG, Carley JC, Fishman EK. Threedimensional volume rendering of spiral CT data: theory and method. Radiographics 1999;19(03):745-764 